\title{
A test of the steel industry's metal
}

\author{
By Prachi Patel \\ Feature Editor Sridhar Seetharaman
}

$T$ he steel industry might not be the bastion it was half a century ago, but it's still a pillar of the world economy. Its product is used in virtually every sector, from transportation and construction to power and electronics. It employs over eight million people worldwide. More than 1.5 billion tons of steel were made in 2012, up from 0.85 billion tons in 2001.

For being such a behemoth, the industry is pretty lean and efficient. Steel, an alloy of iron and carbon, is the most recycled industrial material in the world. About $97 \%$ of steel products can be reused. And making a ton of the metal uses $30 \%$ less energy today than it did two decades ago.

But steel production is still energy-intensive. The industry consumes $5-6 \%$ of all globally generated power and accounts for $6.7 \%$ of all $\mathrm{CO}_{2}$ emissions: Making a ton of steel emits about 1.8 tons of $\mathrm{CO}_{2}$.

Steelmakers have thus far increased energy efficiency mainly by tweaking existing plants and processes. Rising raw material and energy costs as well as stricter environmental regulations are driving some to make steel production yet more streamlined and efficient. A handful of companies are testing breakthrough technologies that could change the way steel is made in 2020 and beyond.

"We know that consuming energy has environmental implications, and that we need to find ways to reduce energy consumption or reuse excess waste energy," said Debashish Bhattacharjee, director of research, development, and technology at Tata Steel. "This is an active area of concern and action in the steel industry."

Making steel typically involves first reducing iron ore to iron and then converting the iron to steel. In the first step, iron oxide ore, coke, and limestone are injected into the top of a blast furnace while pre-heated air is blown into the bottom. The preheated air reacts with the coke (carbon) to give carbon monoxide. This $\mathrm{CO}$ then reacts with the iron oxide to produce molten iron and carbon dioxide.

The process carries enormous energy baggage. Pre-heating air uses energy. So does making coke, which requires cooking crushed coal at temperatures of $1100^{\circ} \mathrm{C}$ in the absence of oxygen. What's more, low-iron-content ore has to be fired in a furnace to produce larger sized pieces called pellets and sinter. All told, blast furnace iron reduction accounts for $80 \%$ of $\mathrm{CO}_{2}$ created during steel manufacture.

In the second step, iron is converted to steel in a basic oxygen furnace by blowing pure oxygen at supersonic speed into the molten iron. This burns the excess carbon present in iron, resulting in $\mathrm{CO}$ and $\mathrm{CO}_{2}$ emissions.

Some manufacturers are already making a dent in energy use by employing simple steps: capturing and reusing byproduct gases for heat and to generate electricity; using pulverized coal instead of coke; and using better thermal insulation. These measures are easy and inexpensive to install at existing plants.

However, the ideal sustainable steelmaking process is one that not only cuts energy use, but is also flexible in terms of raw materials and energy source, Bhattacharjee said. It would use low-quality, low-cost coal and iron. And it would allow a switch from coking coal to natural gas, biomass, or even clean electricity sources. But any such disruptive technology would require enormous capital expenses and support from governments or large industrial consortia.

Europe has been a leader in this regard. Driven by the European Union's (EU's) climate policy framework, the European Commission has made innovation in the steel industry a priority. In 2004, the European Commission and European steel industry launched the ULCOS (Ultra-Low Carbon Dioxide Steelmaking) program, a consortium of 48 companies and organizations with the goal of reducing the carbon emissions from steel production by $50 \%$. ULCOS has invested USD $\$ 725$ million in breakthrough steelmaking technologies, all at various developmental stages.

One, developed at the Tata Steel plant in IJmuiden, The Netherlands, and dubbed HIsarna, has captured the interest of steel- and policymakers. The process takes place in a special reactor that has a narrow cyclone furnace on top of a wider convertor. Pulverized iron ore, coal dust, and oxygen are injected into the cyclone furnace, where the ore partially reduces and melts, falling down to the convertor. Oxygen and coal introduced in the convertor form $\mathrm{CO}$ that finishes reduc- 
ing the melted iron, creating hot gases that rise and provide heat for the reaction occurring in the cyclone furnace.

The technology does not need coke, sinter, or pellets, making it $30 \%$ more energy efficient and $25 \%$ less $\mathrm{CO}_{2}$-intensive than a conventional blast furnace. Plus, it can work with cheaper non-coking coal (e.g., Pittsburgh Seam Coal), which contains volatile matter and low-quality iron ore, enabling flexibility on raw materials.

Pilot tests at a plant producing 8 tons of iron an hour have confirmed the researchers' predictions on HIsarna's reduced energy use and $\mathrm{CO}_{2}$ emissions. A commercial-scale plant would have to be 30-40 times bigger, Bhattacharjee said, which would take more time and investment. For now, companies in the ULCOS consortium as well as the governmentowned Steel Authority of India Limited are interested in moving the technology forward.

In the United States, $60 \%$ of steel comes from scrap steel recycled in an electric arc furnace (EAF), where an electric arc produced between two electrodes melts the scrap. The melt is then refined and cast into products. Scrap reuse eliminates the energy needed to reduce iron ore and make coke. Plus, the mini-mills that employ EAFs have a fifth of the capital cost of traditional steel mills that start with iron ore.

However, there might not be enough scrap to meet market demand; the recycling rate for steel in the United States was $92 \%$ last year, according to the Steel Recycling Institute. Besides, impurities in scrap such as copper and tin can cause cracking of the steel during casting, and this necessitates that the scrap is diluted with iron to lower the effects of the impurities. So US-based recycled steel producer Nucor is taking advantage of the recent shale gas boom in the country to employ a new route at its upcoming steel plant in Louisiana. This plant converts natural gas in a reformer to hydrogen and $\mathrm{CO}$, which together strip oxygen from iron oxide to give so-called direct-reduced iron (DRI). The DRI pellets are then mixed with scrap and fed into an EAF. By eliminating coking coal, DRI reduces the energy use and carbon footprint of steelmaking.

Korean steel giant POSCO and Austrian plant-builder Siemens VAI, meanwhile, have developed a promising technique called FINEX that replaces blast furnaces. Here, fine iron ore is charged in a series of fluidized-bed reactors. A reactor gas made from gasified coal flows in the opposite direction over the ore, heating and reducing it to give DRI. The fine DRI is then smelted to make molten iron. Compared to blast furnaces, FINEX plants are less expensive to build; do not need coke, sinter, or pellets; can use lower quality iron and coal; and produce significantly less sulfur oxide and nitrogen oxide pollutants.

Electrolysis offers another option to make the steelmaking process greener. The method, in which an electric current is passed through molten ore, is commonly used to produce metals such as aluminum. ULCOS has led to two experimental electrolysis processes to produce iron, while researchers at the Massachusetts Institute of Technology are developing lowcost electrolysis methods. "Electrolysis is promising but it uses a lot of electricity so you need a sustainable energy source," said Rob Boom, a materials science and engineering professor at the Delft University of Technology in The Netherlands. "The process is also limited by the surface area of the electrode and impurities in iron ore.'

Of course, whether these innovative low-energy, low-carbon technologies make it to the market and gain widespread adoption is anyone's guess.

In the long term, the situations in developing countries will most significantly shape the steel industry's energy footprint. China currently produces half of the world's steel, but its plants are much less energy-efficient than those in North America, Europe, Japan, and South Korea. "Chinese companies need to make a lot of steel very fast," Boom said. "They're not in business to test advances." The energy consumption of Indian steel plants, meanwhile, is $50 \%$ higher than the global best practice, according to the Economic Times.

Developing markets, however, are also conducive to highrisk transformative technologies, Bhattacharjee said. These nations have booming infrastructural needs; significant government support; room for investments and improvements in industrial practice; abundant low-quality iron and coal; and increasing sustainability pressures. "China and India are roughly five years behind Europe in terms of environmental norms," he said. "But it's just a matter of time before they catch up." 